\title{
The First Total Synthesis of Cocaine
}
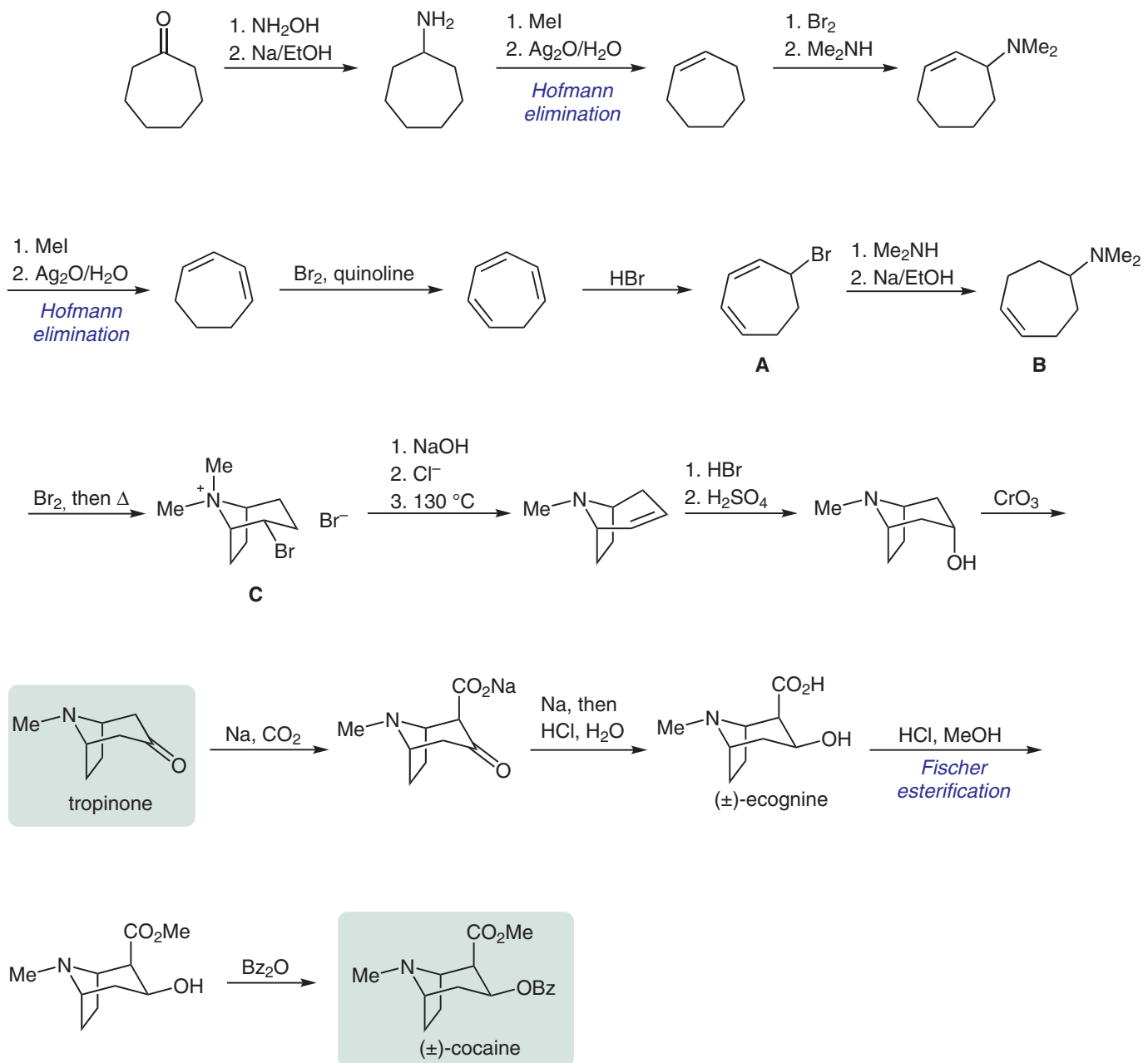

Significance: In 1901, Richard Willstätter and Adolf Bode reported one of the first vollständige Synthese (complete or total synthesis) of a complex natural product. In this seminal work, the authors began their synthesis from cycloheptanone and, in 23 linear steps, completed the synthesis of ( \pm )-cocaine. The key step is a bromination followed by an intramolecular transannular $\mathrm{S}_{\mathrm{N}} 2$ to form the tropane skeleton (Chem. Ber. 1901, 34, 129).
Comment: Cycloheptanone was elaborated to allylic bromide $\mathbf{A}$, which was reductively aminated to afford the precursor $\mathbf{B}$ to the tropane skeleton. The key intramolecular transannular $S_{N} 2$ reaction was achieved upon exposure to $\mathrm{Br}_{2}$ and the resulting salt $\mathrm{C}$ was further manipulated to complete the synthesis of tropinone. Finally, an $\alpha$-carboxylation, dissolving metal reduction, Fischer esterification, and a benzoylation afforded $( \pm)$-cocaine, to complete one of the first examples of a total synthesis. 